\title{
A Informalidade no Mercado de Trabalho Brasileiro: Uma análise da realidade do trabalho no município de Campina Grande-PB
}

\author{
Lizandra Kelly de Araújo Santana*,
} Universidade Federal de Pernambuco, Recife - PE, Brasil

Julio Vitor Menezes dos Santos, Universidade Estadual da Paraíba, Campina Grande - PB, Brasil

Ruan Michel da Silva, Universidade Estadual da Paraíba, Campina Grande - PB, Brasil

Geraldo Medeiros Junior Universidade Estadual da Paraíba, Campina Grande - PB, Brasil

Recebido em 17 de Junho de 2016. Aceito em 7 de Agosto de 2016 RESUMO

Desde o início da década de 1980 as mudanças no mundo do trabalho, decorrentes da restruturação produtiva do capital, têm caracterizado o mercado de trabalho com uma elevada fração de trabalhadores sem contrato formal. No Brasil, este problema pode ter sido amenizado pelo fato de existir a obrigatoriedade de carteira assinada para todos os trabalhadores assalariados. No entanto, com a crise econômica dos anos oitenta, há significativo aumento da informalidade. São muitas as condicionantes que levam as pessoas à informalidade. Uma das principais surge do descompasso existente entre as exigências do mercado de trabalho formal e as condições de qualificação. Este trabalho tem como objetivo analisar a realidade do trabalho informal no município de Campina Grande-PB. Esta pesquisa caracteriza-se como documental. As informações foram obtidas através de pesquisa no site eletrônico “'Atlas Brasil”, desenvolvido pelo IPEA. Os resultados mostraram que embora o grau percentual dos empregados "formais” seja superior ao grau dos "informais”, torna-se relevante um estudo mais aprofundado quanto às causas que levam ao crescimento da economia informal no município em estudo, tendo em vista a possibilidade de essas pessoas ficarem expostas à precariedade das relações de trabalhos. Como conclusão, observa-se a necessidade de existência de políticas públicas adequadas para a região, que objetivem aumentar o emprego e auxiliem a proporcionar um mais elevado nível de bem-estar da população como um todo, contribuindo assim para um desenvolvimento local.

Palavras-chave: mercado de trabalho; trabalho informal; campina grande ABSTRACT

Since the early 1980s the changes in the labor market, resulting from productive capital restructuring, have characterized the labor market with a high fraction of workers without a formal contract. In Brazil, this problem could have been mitigated by the fact that there is a requirement for a formal contract for all employees. However, with the economic crisis of the eighties, there is significant increase in informality. There are many conditions that lead people to informality. One of the main surge of the mismatch between the demands of the formal labor market and the qualifying conditions. This work aims to analyze the reality of informal work in the city of Campina Grande-PB. This research is characterized as documentary. The information was obtained by searching the electronic site " Atlas Brazil ", developed by IPEA. The results showed that although the percentage degree of employees 'formal' is higher than the degree of "informal" further study becomes relevant as to the causes that lead to the growth of the informal economy in the city under study, in view of the possibility these people are exposed to the precarious relations work. In conclusion, there is the need for the existence of appropriate public policies for the region, that aim to increase employment and assist to provide a higher level of the population's well-being as a whole, thus contributing to local development.

Keywords: Labor Market; informal work; campina grande

* Autor para correspondências. Lizandra Kelly de Araújo Santana

e-mail: lizandraaraujo.adm@gmail.com 


\section{Introdução}

A participação da economia informal nos resultados econômicos tem apresentado tendência plena ao crescimento no mundo nos últimos anos. Com a expansão do setor de serviços, setor caracterizado pelo alto grau de informalidade apresentado, é possível observar claramente a tendência à maior elevação do mesmo, seja em caráter formal ou informal.

Na visão de Smith (1994) para compreender a economia informal é importante trabalhar como a "produção de bens e serviços baseados no mercado, legal e ilegal, que escapa da detecção das estimativas oficiais do Produto Interno Bruto". Neste trabalho serão consideradas apenas as atividades informais legais, uma vez que como lembra Smith (1994), as atividades ilegais não são reconhecidas como legítimas quando da contagem do Produto Interno Bruto.

As atividades formais legais são as práticas econômicas "socialmente aceitas", mas omissas aos órgãos tributadores, visto que "não cumprem as obrigações impostas pelo Estado, no que se refere aos tributos e à regulação" (DE SOTO, 1989). Isto significa que as reformulações de trabalho advindas do processo de globalização, apresentam uma perspectiva materialista exacerbada, o que resulta em uma compreensão equivocada do trabalho. (MAGALHÃEE, 2001).

É um erro não considerar a economia informal como grande contribuição para a formação do PIB, em especial no Brasil. Segundo pesquisa do Instituto Brasileiro de Ética Concorrencial (2013), a economia informal movimentou $\mathrm{R} \$ 782$ bilhões em 2013, o que corresponde a 16,2\% de tudo o que o Brasil produziu formalmente no mesmo ano, mas tais números não contam oficialmente na composição do PIB brasileiro.

Formada em sua maioria pelos pequenos negócios, como será visto nos itens a seguir, os incluídos na economia informal possuem diversas razões para recorrer à informalidade. Decorrente disto questionase: Em relação à informalidade qual é a realidade do trabalho no município de Campina Grande-PB? Este trabalho tem como objetivo analisar a realidade do trabalho informal no município de Campina Grande-PB

$\mathrm{O}$ artigo está estruturado da seguinte forma: será feito a seguir um resgate histórico e conceitual do tema em foco. Em seguida serão apresentados os procedimentos metodológicos. Por fim, a análise e descrição dos resultados.

\section{Fundamentação Teórica}

\subsection{Relações de Trabalho}

A evolução das forças produtivas e a complexidade das condições de trabalho no modo de produção capitalista trazem à tona uma maior agressividade do capital contra o trabalho, o que se traduz numa divisão do trabalho mais perversa para a classe trabalhadora.

A divisão de trabalho traz consigo, uma separação entre trabalho intelectual e manual, culminando, de acordo com Ferreira Junior (2008) na "elitização dos conhecimentos de produção, que ficam restritos aos dirigentes das organizações". A elitização e privatização do conhecimento intelectual, bem como toda a produção, torna-se mais organizado com o surgimento da propriedade privada e do Estado, criando uma sociedade estratificada, onde uma classe detinha os meios de produção e a outra não detinha.

No contexto brasileiro, a abertura comercial promovida por Collor em 1990, deu início a processos de reestruturação produtiva trazendo grandes mudanças estruturais. Paralelamente, duas transformações ocorreram no que tange o funcionamento do mercado de trabalho: a) os regimes de trabalho são flexibilizados; e b) o sistema de proteção ao trabalho é desregulamentado, trazendo riscos à garantia de direitos dos trabalhadores. Em sintonia com os objetivos do capitalismo contemporâneo, a flexibilização do trabalho está aliada a precarização dos direitos sociais e trabalhistas.

A Informalidade no Mercado de Trabalho Brasileiro: Uma análise da realidade do trabalho no município de Campina Grande-PB Lizandra Kelly de Araújo Santana, Julio Vitor Menezes dos Santos, Ruan Michel da Silva e 
Com o capitalismo, as relações entre homens e homens (relações sociais) tornam-se relações entre homens e coisas. O que é definido por Lukács (1974) como o "processo de reificação", onde o ser humano é igualado à condição de ferramenta, desconsiderando-o como um ser com anseios e necessidades. Isso se dá devido ao fato da força de trabalho ser cada vez mais substituída pela máquina, e pelo de os indivíduos que terem apenas a força de trabalho a oferecer (MAGALHÃES, 2001). Isto significa que as reformulações de trabalho advindas do processo de globalização, apresentam uma perspectiva materialista exacerbada, o que resulta em uma compreensão equivocada do trabalho.

A reestruturação no processo produtivo trouxe consigo fechamento de fábricas, terceirização, subcontratação, reorganização dos processos produtivos com o intuito de racionalizar os custos, principalmente os custos de produção. Essas agressivas reformas culminaram em números alarmantes quanto ao crescimento do desemprego.

A permanência de qualquer assalariado no mercado de trabalho depende da sua contribuição para a manutenção do sistema que está inserido, e para isso é de extrema necessidade que se adeque às exigências de mercado. Os excluídos do processo produtivo tinham que encontrar um novo meio de sobrevivência e veem alternativa no trabalho informal como camelôs, fretistas, vendedores de porta em porta, entre outros, o que permite apenas garantir a sobrevivência do indivíduo e de sua família, não dando oportunidade a se alcançar o consumo do sonho capitalista (MAGALHÃES, 2001).

\subsection{Precarização do Trabalho}

O processo de precarização do trabalho diz respeito à constituição violenta de degradantes condições de trabalho, que mesmo estando presente desde os empregados formais e temporários, está sempre mais visível no âmbito informal.

Esse processo teve início com as mudanças estruturais inseridas no sistema capitalista, antes centrado no capital industrial e agora focado em um sistema de produção de capital mais flexível, como o mercado financeiro.

\section{Segundo Araújo (2013):}

No século XX, o capital organizado concentrou-se e expandiu-se com uma supervalorização das instituições financeiras que tenderam a dispensar a contribuição do capital produtivo industrial. $\mathrm{O}$ cenário de crise mundial da primeira década deste século aponta o processo de acumulação em níveis altos e o aperfeiçoamento da gestão da força de trabalho, para alcançar maior competitividade, elevar a produtividade e garantir a lucratividade. [...] Desestruturada, a relação de emprego padrão, onde prevalece o trabalhador assalariado formal, o trabalho remunerado que garante reconhecimento social entrou em convulsão com as renovadas crises da acumulação. (ARAÚJO, 2013)

No que diz respeito ao Brasil, as mudanças mais significativas ocorreram a partir dos anos de 1990, em especial com a vigência dos governos de Fernando Collor de Melo e Fernando Henrique Cardoso, período no qual a economia do país passou pela abertura comercial - rompendo com a política de substituição de importações. Essa nova política, de adaptação competitiva ao mercado global deu início a processos generalizados de reestruturação produtiva dentro das empresas. O fechamento de fabricas, enxugamento de plantas, redução de hierarquias, concentração de produção nas áreas ou produtos de maior retorno, terceirização, entre outros, apareceram como estratégia para à sobrevivência das organizações. Resultando em um fenômeno de demissão em massa nunca antes visto na história da industrialização brasileira (COSTA, 2005).

A Informalidade no Mercado de Trabalho Brasileiro: Uma análise da realidade do trabalho no município de Campina Grande-PB Lizandra Kelly de Araújo Santana, Julio Vitor Menezes dos Santos, Ruan Michel da Silva e

Geraldo Medeiros Junior 
À luz do fenômeno, a informalidade se apresenta como forma de inserção no mercado consumidor, e mesmo como estratégia de sobrevivência àqueles isentos de participação no processo industrial. Percebe-se então a formação de dois blocos: o primeiro, dos trabalhadores com seus direitos assegurados pela lei, empregados formalmente; e o segundo, dos "desempregados", acolhidos pela flexibilidade do mercado informal, coagidos pela falta de opção, de qualificação suficiente para ocupar postos de trabalho e pela indisponibilidade de postos a serem ocupados por eles. Sendo ainda possível, a observância de um terceiro bloco, este composto pelos trabalhadores em regimes de trabalho que os propiciam a ocupação em ambas as vertentes do emprego (formal e informal) levados pela necessidade de geração de renda para sua subsistência.

\subsection{Economia Informal}

O crescimento da informalidade nas últimas décadas tem sido um importante nos últimos anos. Ribeiro e Bugarin, afirmam que a economia submersa ou economia informal aparece em menor proporção em países desenvolvidos, caracterizados também por possuírem uma renda mais alta.

Nos países subdesenvolvidos observa-se um alto nível de informalidade, justificado pela alta carga tributária e discricionariedade regulatória, aliadas a grande incidência de práticas de suborno e a uma autoridade de lei considerada fraca. Ribeiro adiciona ainda mais algumas variáveis que influenciam o ingresso no mercado informal. São eles: redução forçada do tempo de trabalho; aposentadoria precoce; desemprego; inflação; o declínio da percepção de justiça e lealdade para com as instituições públicas; a redução do índice de moralidade; redução do índice de percepção da corrupção, o que indica aumento desta; e, até mesmo a liberdade, como fator de escolha dos indivíduos para trabalhar na informalidade.

Uma das principais razões para a informalidade surge com desacordo entre as exigências do mercado de trabalho e as condições de qualificação, de disciplina e de hábitos de parte substancial da mão de obra. Pode surgir também com a dificuldade do mercado de mão de obra de encontrar um emprego formal, ou quando encontrado, gera-se insatisfação quanto aos salários baixos e falta de planos de carreira. Mas, ainda que a entrada na informalidade seja voluntária ou não, muitas vezes, as pessoas escolhem permanecer na informalidade como forma de vida. Explicando esse fenômeno, Menezes \& Dedecca (2012) afirmam que

[...] A estrutura ocupacional da informalidade é complexa e heterogênea, mas, pelo menos para muitas pessoas, ela oferece muitas possibilidades. É natural, portanto que muitos indivíduos prefiram ficar na informalidade, exatamente porque aí encontram suas melhores oportunidades de trabalho e renda; outros tantos, por não disporem dos requisitos necessários ao mercado formal, acabam ficando na informalidade por absoluta falta de alternativa; e, outros ainda entram e saem da informalidade conforme as altas e baixas conjunturais do nível da atividade econômica como um todo (MENEZES e DEDECCA, 2012).

A informalidade traz em seu escopo a ausência dos direitos trabalhistas, figurado essencialmente pelo não registro nos órgãos competentes e pela não contribuição à previdência social, como afirmam Menezes \& Dedecca (2012):

A não contribuição à previdência é a síntese da perda de direitos, na medida em que essas pessoas enfrentem cotidianamente uma difícil decisão pessoal: alocar recursos para a contribuição da previdência social em detrimento da renda presente ou dispor uma renda presente mais elevada, mas em detrimento de suas condições futuras de existência. Dessa forma, essas pessoas ficam expostas a uma precariedade da relação de trabalho, podendo a enfrentar graves problemas econômicos no final de suas vidas profissionais, já que não serão cobertos pelo sistema de previdência social. Nesse momento, essas pessoas acabam ficando a mercê de familiares ou de benefícios do sistema de seguridade social (após certa idade e segundo determinadas condições), onerando toda a sociedade. (MENEZES \& DEDECCA, 2012)

Apesar de seus pontos fracos, a informalidade tem seus benefícios. Segundo Asea (1996, apud RIBEIRO e BUGARIN), a economia informal pode levar o mercado a uma maior competitividade, trazendo maior eficiência e delineando limite à ação do governo, adicionando dinamismo e espirito empresarial à 
economia. Sendo acrescido do ponto de vista de Schneider e Enste (2000, apud RIBEIRO e BUGARIN) que a partir de seus estudos sugerem que cerca de $66 \%$ da renda gerada no setor informal do trabalho é empregada no setor formal, beneficiando o crescimento econômico e a receita arrecadada com os impostos indiretos.

Dessa forma, é notória a relação de dependência estabelecida entre os mercados formal e informal, mesmo o segundo não sendo prioridade em detrimento do primeiro, por ostentar um caráter "ilegal". A despeito dessa diferenciação, a relação estabelecida acaba por trazer vantagens para ambas às partes, interessadas em sonegar as tributações exacerbadas impostas pelo sistema econômico nacional/governamental, podendo ser reduzida a um termo: mutualismo.

A intervenção governamental diante da questão assume forte valor ao controle da informalidade, que ao atingir níveis elevados, representa ameaça ao sistema econômico nacional. Assim, a criação de políticas econômicas efetivas, que caminhem contra as variáveis indutoras da informalidade, que trazem consigo, não somente as mazelas do fenômeno, deve assumir prioridade no setor público, que tem como uma de suas principais atribuições, a manutenção do bem-estar social dos indivíduos.

\section{Aspectos Metodológicos}

O presente artigo foi construído como pesquisa documental, a partir de consulta de fontes secundárias, especialmente aquelas obtidas através de pesquisa no sítio eletrônico do Atlas do Desenvolvimento Humano no Brasil. Foram consultados os indicadores desenvolvidos por meio de pesquisa realizada pelo Instituto de Pesquisa Econômica Aplicada (IPEA), tendo como bases o Censo 2010. Tais indicadores deram subsídio a elaboração de um comparativo entre a realidade nacional com a realidade apresentada para o município de Campina Grande, estado da Paraíba.

Diante do exposto, o que se pretende com este artigo é utilizar os dados como contraponto, tendo como base uma comparação em relação aos resultados nacionais com os resultados apresentados no município de Campina Grande-PB, foco deste estudo. Assim, a informalidade é discutida a partir de alguns indicadores objetivos. Longe de se pretender esgotar o debate sobre o tema, antes se pretende aqui iniciar uma discussão à luz da administração política.

A problemática em questão, busca respostas acerca das causas de elevado índice de informalidade. $\mathrm{O}$ foco deste trabalho consiste em analisar e realizar comparativo entre a média nacional com a realidade campinense, visando a geração de informações no que diz respeito ao grau de informalidade, bem como dos condicionantes básicos para a composição da mesma.

\section{Resultados e Discussões}

\subsection{Caracterização e IDHM de Campina Grande-PB}

Segundo o último Censo Demográfico, Campina Grande, situada no estado da Paraíba, tinha em 2010, cerca de 385.213 habitantes, sendo: 182.205 homens (47,30\%) e 203.008 mulheres $(52,70 \%)$.

O Índice de Desenvolvimento Humano (IDHM), que busca mensurar desenvolvimento humano entre municípios escolhidos, de Campina Grande era 0,720, em 2010, o que pode ser considerado como IDHM alto (IDHM entre 0,700 e 0,799), enquanto o IDHM da Paraíba era 0,658, sendo considerado como médio (IDHM entre 0,600 e 0,699). Dos componentes que formam o IDHM, o que mais contribui é a Longevidade, com índice de 0,812, depois o de Renda, com índice de 0,702, e por último de Educação, com índice de 0,654, como pode ser observado nos dados abaixo:

A Informalidade no Mercado de Trabalho Brasileiro: Uma análise da realidade do trabalho no município de Campina Grande-PB Lizandra Kelly de Araújo Santana, Julio Vitor Menezes dos Santos, Ruan Michel da Silva e

Geraldo Medeiros Junior 


\section{Tabela 1: IDHM e seus componentes}

IDHM e seus componentes 2010

0,654

\subsection{IDHM Educação}

$\%$ de 18 anos ou mais com ensino fundamental completo

$\%$ de 5 a 6 anos frequentando a escola

$\%$ de 11 a 13 anos frequentando os anos finais do ensino fundamental

85,08

$\%$ de 15 a 17 anos com ensino fundamental completo

53,16

\% de 18 a 20 anos com ensino médio completo

44,14

IDHM Longevidade

0,812

Esperança de vida ao nascer (em anos)

73,73

IDHM Renda

0,702

Renda per capita (em $\mathrm{R} \$$ )

630,03

Fonte: PNUD; IPEA; Fundação José Pinheiro; Censo 2010.

Campina Grande ocupa a $1301^{a}$ posição entre os 5.565 municípios brasileiros segundo o IDHM. Nesse ranking, em nível Brasil, o maior IDHM é o de São Caetano do Sul, situado no estado São Paulo, com índice de 0,862 e o menor é de Melgaço, situado no estado do Pará, com índice de 0,418. Quanto em nível estadual, Campina Grande-PB ocupa a $3^{\mathrm{a}}$ posição, ficando atrás apenas de João Pessoa $(0,763)$ e Cabedelo (0,727).

\subsection{Trabalho}

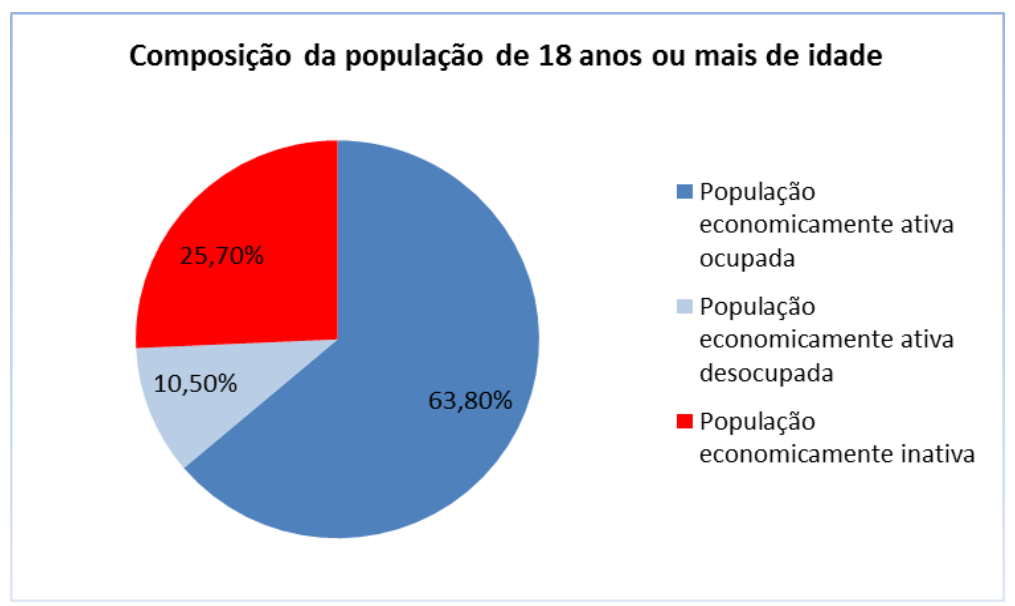

Gráfico 1: Trabalho - Ocupação/Desocupação

Fonte: PNUD; IPEA; Fundação José Pinheiro; Censo 2010.

Como pode ser observado no gráfico 1, em 2010, 174.031 da população de 18 anos ou mais de idade era economicamente ativa em Campina Grande, 28.128 da população no mesmo ano era economicamente ativa desocupada, enquanto 70.060 era considerada economicamente inativa. Ou seja, 63,80\% da população de 18 ou anos ou mais estavam trabalhando, seja remunerado, não remunerado, por conta própria ou como um empregador, 10,50\% não possuíam emprego, mas estavam aptas a trabalhar (estavam em busca de 
trabalho) já $25,70 \%$ da população estavam à margem do mercado, aquelas que não possuem idade, interesse ou condições de exercer algum ofício.

Quanto aos dados da posição dos ocupados, o gráfico 2 mostra que em 2010, apenas 41\% dos ocupados no município de Campina Grande possuem carteira de trabalho assinada, e 20,6\% dos trabalhadores estão ocupados sem carteira assinada, ou seja, estão em situação de vulnerabilidade, pois não são asseguradas pelo sistema de previdência social. Em nível estadual o gráfico mostra que apenas $28,3 \%$ dos ocupados possuem carteira assinada. Embora o grau percentual dos empregados "formais" seja superior ao grau dos "informais", torna-se relevante cada vez mais estudos, discussões que aprofundem mais quanto às causas que levam ao crescimento da economia informal no município em estudo, tendo em vista a possibilidade de essas pessoas ficarem expostas à precariedade das relações de trabalhos, podendo enfrentar sérios problemas econômicos pelo fato de que não serão cobertos pelo sistema de previdência social.

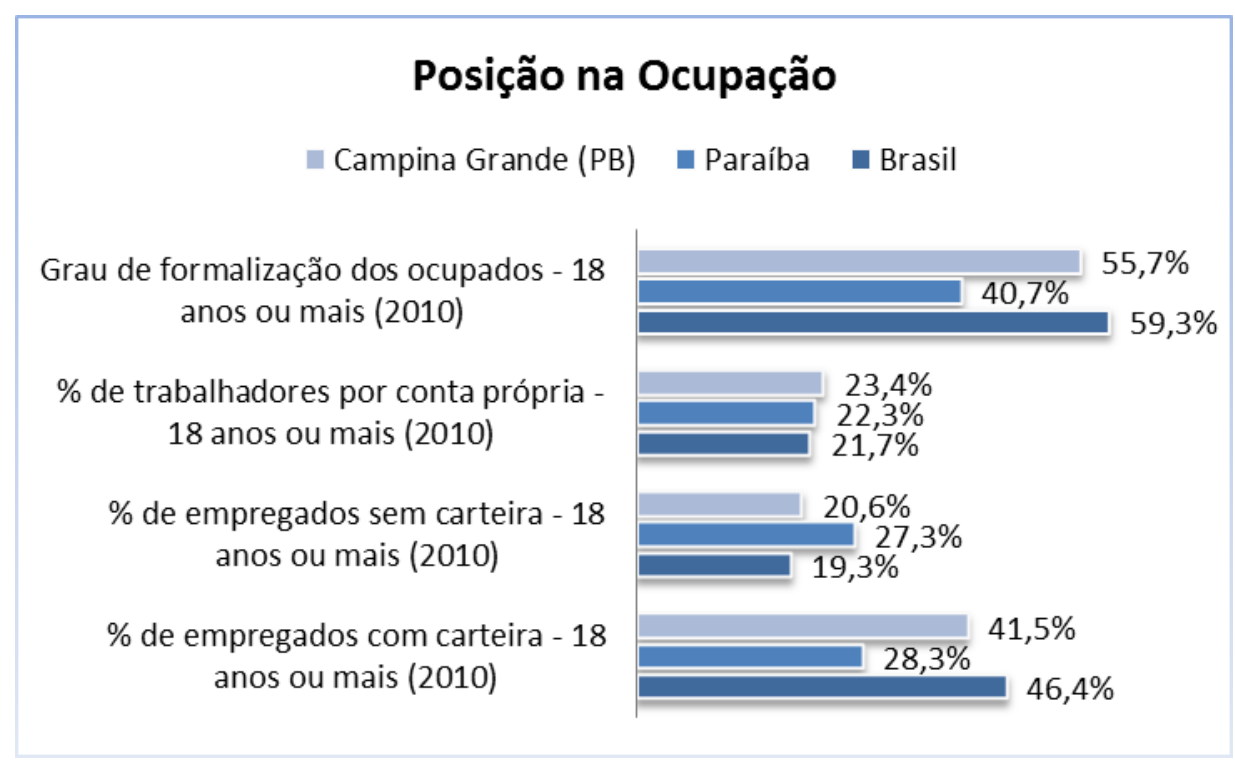

\section{Gráfico 2: Trabalho - Posição na Ocupação}

Fonte: PNUD; IPEA; Fundação José Pinheiro; Censo 2010

Buscando entender a realidade que atinge o município de Campina Grande quanto à informalidade e tendo em vista que a escolaridade é um dos principais fatores de seleção e exclusão ao mesmo tempo, sentiu-se a necessidade de analisar os dados disponibilizados pelo Censo 2010 quanto à escolaridade dos ocupados campinenses em relação aos ocupados em nível estadual e federal. 


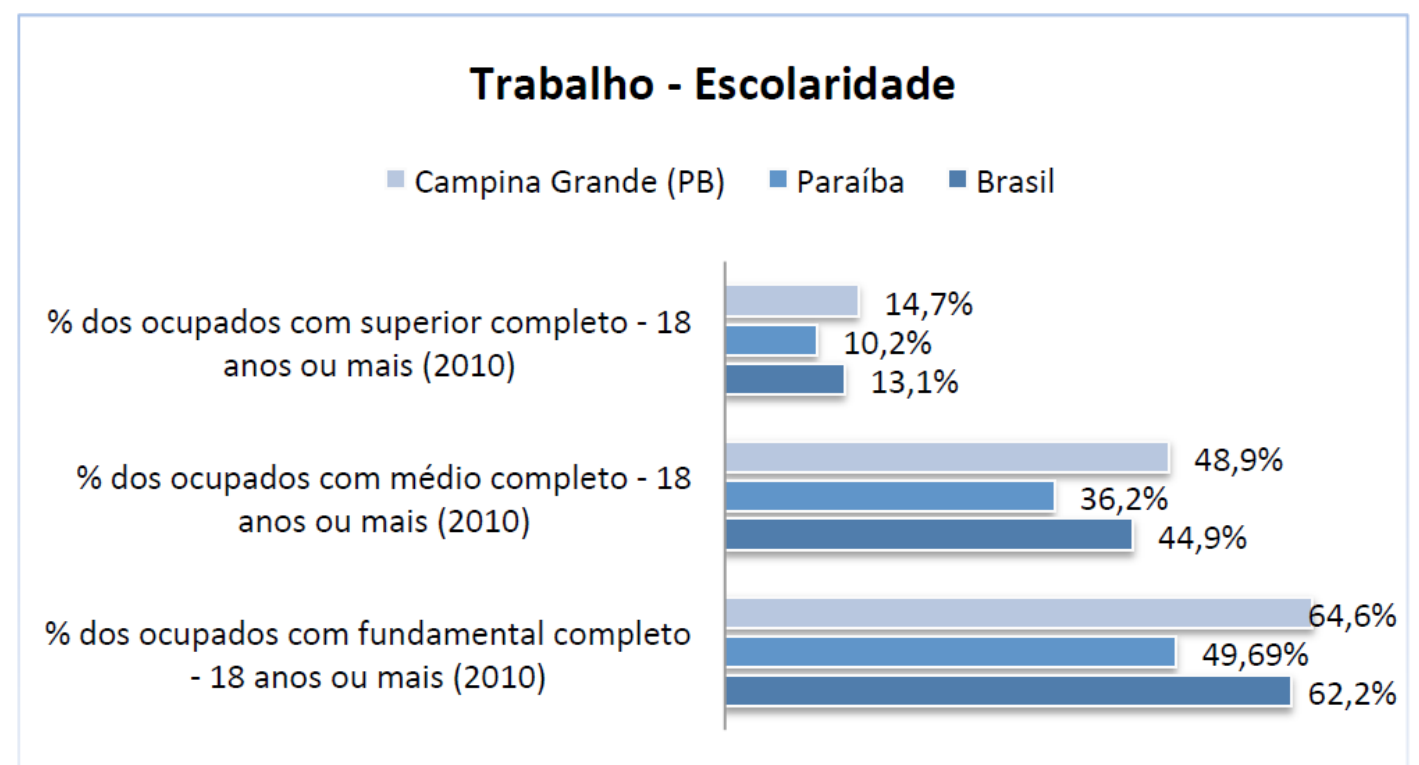

\section{Gráfico 3: Trabalho - Escolaridade}

Fonte: PNUD; IPEA; Fundação José Pinheiro; Censo 2010.

Os dados do gráfico 3 revelam que o grau percentual de ocupados de 18 ou anos ou mais com ensino médio é inferior ao grau percentual de ocupados da mesma faixa etária com ensino fundamental completo e, por sua vez, este é três vezes superior ao grau percentual de ocupados ensino superior completo. Ou seja, $64,6 \%$ dos ocupados com 18 anos ou mais possui apenas o ensino fundamental completo, chegando a ultrapassar a média nacional que é de $62,2 \%$; quanto aos ocupados que possuem ensino médio completo os dados mostra um percentual de 48,9\%; por último, percebe-se que apenas $14,7 \%$ dos ocupados possui ensino superior completo.

Portanto, ao analisar esses dados pode-se afirmar que no município de Campina Grande há um excedente de mão-de-obra com baixo nível de qualificação, o que pode expor grande parte desta população ativa a situações de trabalho precário, como dito anteriormente, quando não o desemprego. $\mathrm{O}$ trabalhador que não tem sua carteira assinada fica privado de benefícios como Fundo de Garantia do Tempo de Serviço (FGTS), seguro-desemprego, abono salarial, auxílio-doença, auxílio-acidente de trabalho, salário maternidade e aposentadoria.

Em 2010, das pessoas ocupadas de 18 anos ou mais do de Campina Grande, 4,38\% trabalhavam no setor agropecuário, 0,39\% na indústria extrativa, 12,38\% na indústria de transformação, 7,33\% no setor de construção, $1,21 \%$ nos setores de utilidade pública, $21,11 \%$ no comércio e $48,75 \%$ no setor de serviços, segundo o Censo 2010. O gráfico 4 deixa claro quanto à disparidade em percentual de pessoas que estão em cada setor. 


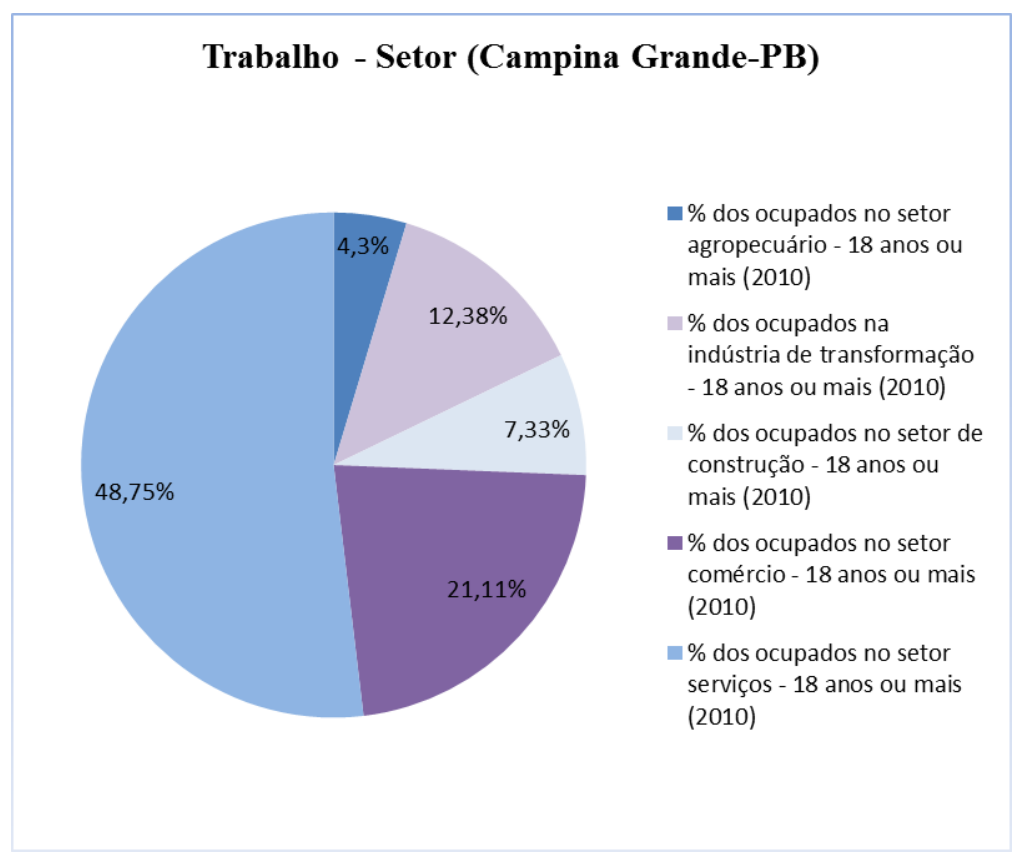

\section{Gráfico 4: Trabalho - Setor}

Fonte: PNUD; IPEA; Fundação José Pinheiro; Censo 2010.

É notório a diminuição dos trabalhadores no âmbito fabril e o crescimento dos assalariados no setor de serviços no Brasil. Como pode ser observado no gráfico 4, 48,75\% da população ocupada, em 2010, compunham este setor. Segundo Almeida e Silva (1973, p. 149150) apud Melo et al (1996), a industrialização e urbanização provocaram um acréscimo da força de trabalho nas atividades terciárias, principalmente nos ramos que exigem menor qualificação. O importante crescimento desse setor é resultado do modo de organização que tem como característica a flexibilização produtiva, no qual as empresas buscam enxugar ao máximo seus custos, por meio da terceirização.

Buscando comprovar o crescimento do setor de Serviços em Campina Grande, vale ressaltar que em 2012 foi instalada no município uma das empresas do setor de telecomunicações, a call center do grupo Contact Center AeC, que gera mais de 2.000 empregos. De acordo com o Sindicato dos Trabalhadores de Telecomunicações do Estado da Paraíba, a grande insatisfação dos trabalhadores da call center tem gerado rotatividade. O sindicato lista que os maiores problemas listados pelos trabalhadores: doenças do trabalho, baixa remuneração, metas inalcançáveis, alimentação de má qualidade e descumprimento da legislação trabalhista.

O último gráfico que compõe a dimensão Trabalho, mostra os dados da população de faixa etária de 18 anos ou mais que estão em situação de vulnerabilidade e que afeta diretamente a economia do município. Ele revela que 35,11\% da população de 18 anos ou mais de Campina Grande não possui ensino fundamental completo e que, em 2010, estava em ocupação informal, ou seja, aproximadamente 47.260 pessoas em situação de vulnerabilidade social. Mais da metade dos trabalhadores da Paraíba são informais, o estado é o quarto país em taxa de informalidade no País, ficando atrás apenas do Maranhão, Piauí e Pará. 


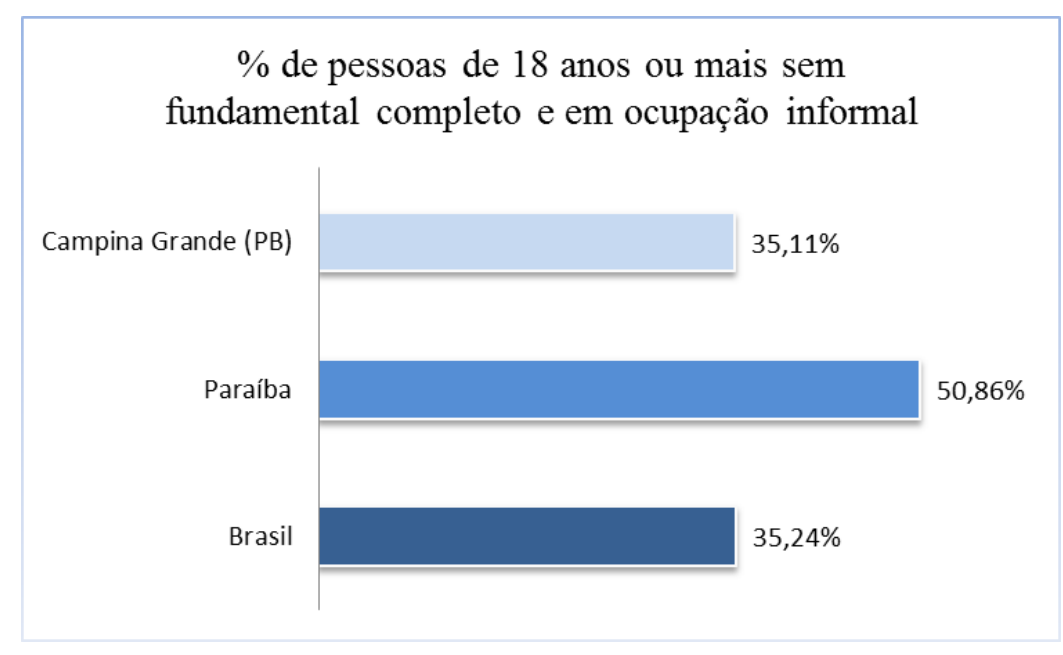

\section{Gráfico 5: Trabalho - Vulnerabilidade}

Fonte: PNUD; IPEA; Fundação José Pinheiro; Censo 2010.

Não se pode negar que a realidade dos trabalhadores campinenses, muitas vezes sem qualificação e com a impossibilidade de encontrar empregos ou com a expectativa de salários baixos no mercado formal contribua para a migração de muitos campinenses para a informalidade.

Pode-se considerar complexa a estrutura ocupacional da informalidade, pois para alguns trabalhadores, optar pelo trabalho informal significa oferecer melhores condições de trabalho, uma vez que eles não estarão recebendo ordens de outras pessoas. Portanto, sente-se a necessidade de outros estudos relacionados ao trabalho informal no município de Campina Grande que possam responder a preferência de muitos campinenses pelo trabalho informal, se eles preferem ficar na informalidade, porque encontram exatamente suas melhores oportunidades de trabalho e renda ou por não disporem dos requisitos necessários ao mercado formal campinense, ou seja, buscam a informalidade pela falta de alternativa.

\subsection{Educação}

A educação é um dos principais fatores que contribuem para a qualidade mercado de trabalho. Tentando entender o porquê do aumento da economia informal no município, os autores do presente estudo acharam pertinente mostrar os dados e como anda a educação campinense. Como pode ser visto no gráfico abaixo, em 2010, em Campina Grande eram 12,39\% analfabetos, o percentual da população de 18 anos ou mais com o ensino fundamental completo era de $57,44 \%$ e $41,83 \%$ possuía ensino médico completo. No Brasil, esses percentuais são, respectivamente, $10,19 \%, 54,92 \%$ e $37,89 \%$. 


\section{Escolaridade da população de 18 anos ou mais - 2010}

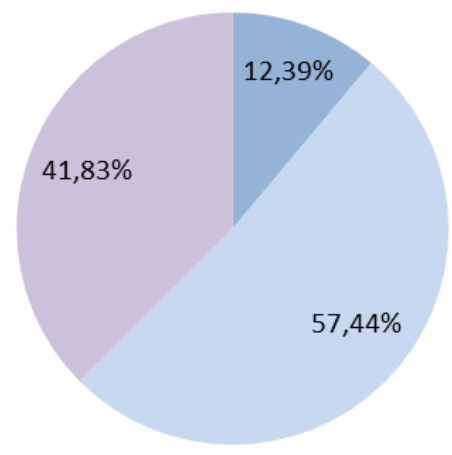

- Taxa de analfabetismo 18 anos ou mais (2010)

$\%$ de 18 anos ou mais com fundamental completo (2010)

- $\%$ de 18 anos ou mais com médio completo (2010)

\section{Gráfico 6: Educação}

Fonte: PNUD; IPEA; Fundação José Pinheiro; Censo 2010.

Para Coutinho (2007), no Brasil a concentração de renda atinge níveis elevadíssimos, restringindo a uma minoria o acesso aos bens de consumo mais sofisticados e as condições mais favoráveis de educação, enquanto que a grande maioria se encontra sem as mesmas condições de acessar estes fatores e concorrer às mesmas oportunidades no mercado de trabalho.

A falta de qualificação da grande maioria dos ocupados no município de Campina Grande contribui para a fragilidade do mercado de trabalho campinense. Com o grande índice de mão de obra não qualificada, as empresas encontram no mercado de trabalho campinense cada vez mais espaço para que as mesmas consigam sua ascensão.

\subsection{Vulnerabilidade Social}

Outro fator que pode contribuir para a ascensão da economia informal no município é o de Vulnerabilidade Social.

A Informalidade no Mercado de Trabalho Brasileiro: Uma análise da realidade do trabalho no município de Campina Grande-PB Lizandra Kelly de Araújo Santana, Julio Vitor Menezes dos Santos, Ruan Michel da Silva e

Geraldo Medeiros Junior 


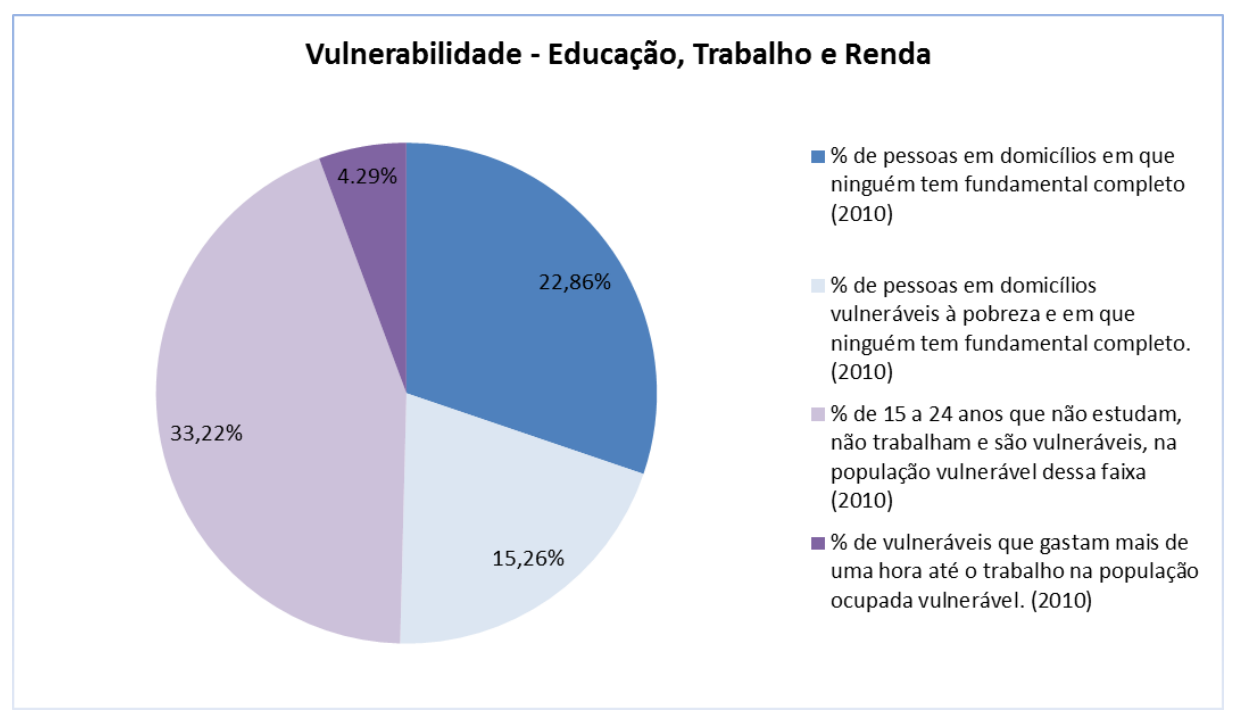

Gráfico 7: Vulnerabilidade - Educação, Trabalho e Renda

Fonte: PNUD; IPEA; Fundação José Pinheiro; Censo 2010.

Os dados acima mostram que $22,86 \%$ de pessoas em domicílios não tem fundamental completo, $15,26 \%$ pessoas em domicílios vulneráveis à pobreza em que ninguém tem fundamental completo, 4,29\% de pessoas que gastam mais de uma hora até o trabalho e por fim e que chama atenção é o fato de $33,22 \%$ de pessoas com idade de 15 a 24 anos que não estudam e não trabalham, ou seja, elaborando o cálculo, (razão entre a quantidade de pessoas de 15 a 24 que não estudam, não trabalham e a população vulnerável nesta faixa etária, depois multiplicando por 100), pode-se considerar que 29.888 pessoas estão em situação de vulnerabilidade no município de Campina Grande, o que corresponde a aproximadamente $7,75 \%$ da população campinense.

\section{Conclusão}

Neste artigo buscou-se discutir sobre os possíveis motivos que contribuem para o alto grau de informalidade na economia de Campina Grande. A vinculação com variáveis a exemplo de escolaridade, nível de renda, é importante. Embora os dados demonstrem que o município segue uma tendência nacional, a perspectiva de criação de uma estratégia própria de desenvolvimento passa pelo enfrentamento deste problema.

Compreende-se também que a força de trabalho que caracteriza o mercado informal no estado da Paraíba, em especial no município de Campina Grande, não consegue manter um processo de qualificação exigida pela nova ordem técnica e organizacional.

Dessa forma, essas pessoas ficam expostas a uma precariedade da relação de trabalho, podendo a enfrentar graves problemas econômicos no final de suas vidas profissionais, já que não serão cobertos pelo sistema de previdência social. Com o aumento dos mecanismos de acomodação de grande parte dos trabalhadores, facilitarão a instalação de empresas que estão em busca de mão de obra não qualificada o que enfraquece ainda mais o mercado local.

A redução dos malefícios deve advir de políticas públicas adequadas, políticas que objetivem melhorar a condição produtiva das pessoas e auxiliem a proporcionar um mais elevado nível de bem-estar da população como um todo, contribuindo assim para um desenvolvimento local mais eficiente. 


\section{REFERÊNCIAS BIBLIOGRÁFICAS}

ASEA, P. K. The informal sector: baby or bath water? Carnegie-Rochester Conf. Series Public Policy 45, p. 163-71, 1996.

BUGARIN, Noemi Sataka. Fatores Determinantes e Evolução da Economia Submersa no Brasil. Receita Federal, Ministério da Fazenda. Departamento de Economia, Universidade de Brasilia. Est. econ., São Paulo, V. 33, n. 3, p. 435-466, Julho - Setembro 2003.

COUTINHO, H. G. Mercado de trabalho, escolaridade e renda no Brasil- 1988 a 1998. Revista do Curso de Administração da Faculdade Maurício de Nassau, v. 2, p. 281-304, 2007.

DE SOTO, Hernando. The Other Path. (El Outro Sendero. Translated by June Abbott) NY: Harper and Row, 1989.

MAGALHÃES, Josiane. Relações de trabalho no Brasil: o movimento auto gestionário como resposta à globalização da economia e seus reflexos no mercado de trabalho. Revista Urutágua. Universidade Estadual de Maringá, 2001.

MELO, Hildete Pereira de; ROCHA, Frederico et al. O Setor Serviços no Brasil: Uma Visão Global - $1985 / 85$. Instituto de Pesquisa Econômica Aplicada - IPEA, 1998.

MENEZES, Wilson F. DEDECCA, Cláudio S. A Informalidade No Mercado De Trabalho Brasileiro: Rendimentos e principais características. Nexos Econômicos. V. 6, n. 2, dez. 2012. CME-UFBA, 2012.

RIBEIRO, Roberto Name. Causas, Efeitos e Comportamento da Economia Informal no Brasil. Mestrado em Economia do Setor Público. Universidade de Brasília, 2000

SCHNEIDER, F.; ENSTE, D. H. Shadow economies: size, causes, and consequences. Journal of Economic Literature, 38 , p. $77-114,2000$.

SMITH, Philip. Assessing the Size of the Underground Economy: the Canadian Statistical Perspectives. Canadian Econ. Observer, Cat. No. 11-010, 3.16-33 a 3.18. 